\title{
THE LONG TERM EFFECTS OF ELECTRONIC COMMERCE AND DATA INTERCHANGE ON FIRMS
}

\author{
Professor François BERGERON \\ Département Systèmes d'information organisationnels \\ Faculté des sciences de l'administration \\ Université Laval \\ Québec, \\ Québec, Canada \\ GIK 7P4 \\ phone: (418) 656-7940 \\ email: Francois.Bergeron@fsa.ulaval.ca \\ fax: (418) 656-2624 \\ and \\ Professor Louis RAYMOND \\ Departement des sciences de la gestion \\ Université du Québec à Trois Rivières \\ C.P. 500, Trois-Rivières \\ Quebec, Canada \\ G9A $5 \mathrm{H} 7$ \\ e-mail : louis_raymond@uqtr.uquebec.ca
}

\begin{abstract}
This research aims to identify the determinants of electronic commerce effectiveness, as well as the variation over time of their effect. A two-phased study was undertaken for this purpose, using EDI as a specific form of electronic commerce. Sixty-five organisations were surveyed twice over a three-year period. In Phase 1, determining factors were found to be the level of organisational support, the rigour of the implementation process, the presence of control procedures, and the level of internal integration, external integration and imposition of EDI. Imposition also has a negative effect on the organisational context of EDI. In Phase 2, the implementation process, internal integration and imposition lost their importance, whereas the effect of imposition on the organisational context became positive. In the future, we expect the security and extemal integration to be the most important success factors of electronic commerce.
\end{abstract}

Keywords : electronic commerce, electronic data interchange, inter-organisational systems, longitudinal study

\section{INTRODUCTION}

Electronic data interchange (EDI) is an application of electronic commerce (EC) that enables commercial partners to transact by exchanging and processing standardised business documents electronically from computer to computer. The number and types of organisations using EDI has grown steadily in recent years. Whole industries are now being integrated through this technology; witness for example, the automotive and air travel industries, food retailers, drugstores and hospitals. While EDI was mostly based on private networks before 1985, value-added networks operated by third parties have been the main providers of this technology up to the mid-nineties. Since then, EDI has also become an Internet-based technology (Wheatman, 1996). While electronic commerce (EC) embraces three basic aspects, namely transactions, information and strategy, EDI is mostly concerned with the transaction aspect of inter-firm relationships. As such, it is considered to be an enduring form of EC (Kalakota and Whinston, 1996) and a key technology for the implementation of interorganisational systems (Sokol, 1995).

EDI has been shown effective by providing numerous advantages to organisations. Among these are improvements in administrative costs and transaction costs, in information quality, in operations management, and in the attainment of a strategic advantage (Bergeron and Raymond, 1992b; Mukhopadhyay, Kekre and Kalathur, 1995). However, there is no consensus on how effective EDI truly is in providing these advantages. Some researchers and consultants doubt that companies and other organisations have realised any significant cost savings or other durable benefits from implementing EDI (Venkatraman and Zaheer, 1990). Others have questioned the possibility of gaining any advantage at all from using this technology, particularly when the use of EDI is imposed by a business partner (Bergeron and Raymond, 1992a). Various conditions should also be met in order to realise these benefits. Among the most frequently mentioned are the need for an adequate level of organisational support, the rigour of the implementation process, the presence of control procedures, and the integration of EDI with the organisation's internal and external processes (Swatman and Swatman, 1991; Cavaye and Cragg, 1995).

Questions remain, however, about the validity of these research results in the long run. Over the last few years, a number of empirical studies dealing with electronic data interchange have been published. Among those, most have employed a cross-sectional research design. Hence, there is insufficient knowledge about the evolution of 
EDI advantages over time. A number of authors have deplored the lack of longitudinal designs in information systems research. As noted by Vitalari (1985), IS researchers are confronted by certain difficulties, one of which being the inability to make statements about the nature and characteristics of longer-term effects of information systems. This is presently true in the case of EDI.

In order to secure the diffusion and effective use of EDI by a larger number of organisations, it is important to have a deeper understanding of the various aspects of this technology. The advantages obtained from the use of EDI by organisations and the conditions under which these advantages can be obtained are the most critical of these aspects. This research aims at identifying the of EDI, the conditions under which this technology can be effective, as well as the variation of these conditions over time.

An empirical study on EDI was previously conducted (Bergeron and Raymond, 1992b), aiming to investigate the advantages achieved through the implementation of EDI, and the determinants of success. That study provided initial insights into benefits organisations can obtain from EDI as well as under what conditions these benefits could be expected. Given its cross-sectional nature, however, it did not provide information on the stability of the observations over time. In order to shed some light on this issue, the purpose of the present study is to answer the two following research questions: What are the determinants of EDI effectiveness? Do these remain the same over time?

\section{CAUSALITY AND EDI EFFECTIVENESS: A CAUSAL MODEL OF EDI EFFECTIVENESS}

A literature review was conducted to elaborate the research design of the initial study (Phase 1) Given the newness of the EDI field at that time, an inductive approach was used to infer the research model. As part of an on-going effort, the present study can be seen as a validation step. In terms of methodology, it is our contention that a time-based research would be most beneficial at understanding critical EDI issues while paving the way for future IS research and theory development.

The research model for this study includes four constructs: the imposition of EDI by business partners, the organisational context (comprised of organisational support, implementation process and control procedures), the level of integration, and the advantages of EDI. It was hypothesised that the imposition of EDI upon business partners has a direct effect on the organisational context and on EDI advantages. The organisational context and the level of integration were also hypothesised to have a direct effect on EDI advantages.

\section{Organisational context}

Organisational context consists of three basic factors. The first one is organisational support. It refers to the various elements and activities conducted by an organisation to assure the effective introduction of EDI. It addresses personnel training, top-management support, and the presence of an organisational structure specific to EDI (Banerjee and Golhar, 1994). The second factor is the implementation process. It includes aspects such as the planning approach to EDI adoption (eg. prototyping or pilot-project) and the evaluation of initial transactions (eg. in-house tests, error rate, transaction costs) (Skagen, 1989). The last contextual factor is the control procedures. Data integrity, data security and standards are the main elements included here (Adolphson and Hansen, 1991).

\section{Integration}

The second construct is the integration of EDI functions both internally and externally. Internal integration of EDI reflects the variety of the value chain functions (orders, shipments, inventory, etc.) interconnected through EDI within the organisation (Sanders, 1992). External integration refers to the variety of the trading partners (eg., clients, suppliers, distributors, etc.) with which the organisation interacts through EDI ( Zaheer and Venkatraman, 1994).

\section{Imposition by partners}

Imposition by partners refers to a firm's obligation to implement EDI to satisfy a major client or supplier. Firms resist implementing EDI under pressure, because of the difficulty of controlling critical aspects of the project such as the timing of the implementation, the EDI function, and the technology involved. Organisations of all sizes may have to adopt EDI only because they have been obligated to do so by a business partner. Expected benefits may vary depending upon the firm's bargaining power (Riggins and Mukhopadhyay, 1994).

\section{EDI advantages}

The advantages of EDI, the dependent construct in the research model, includes various types of operational, managerial and strategic benefits that can be derived from EDI use. These advantages relate to improvements in 
the firm's administrative costs, transaction cycle, operations management, information quality and competitive position (O'Callaghan, Kaufmann and Konsynski, 1992; Raymond and Bergeron, 1996).

\section{RESEARCH HYPOTHESES}

Six variables (organisational support, implementation process, control procedures, internal and external integration, and imposition) were expected to explain the dependent variable (advantages of EDI). Additionally, imposition is expected to affect the organisational context. The research hypotheses are as follows:

Hypothesis \#1: The quality of the organisational support is positively related to the advantages obtained from EDI.

A favourable organisational environment is a necessary condition to obtain advantages from EDI. The support of top-management, the training of personnel and the presence of a dedicated organisational structure have been reported as important dimensions supporting the introduction of EDI (Klein, 1992) and business process reengineering (Champy, 1995).

Hypothesis \#2 The quality of the implementation process is positively related to the advantages obtained from EDI

As with other types of technology, implementing EDI requires a series of activities. These include analysis, testing and implementation, with approaches such as prototyping (Senn, 1992). Moreover, these activities become critical when introducing inter-organisational applications, such as computerised reservation systems (Raymond and Bergeron, 1997). It is expected that a similar relationship will be observed in the case of EDI.

Hypothesis \#3: The quality of the control procedures is positively related to the advantages obtained from EDI.

Control procedures are meant to assure data security and integrity. Making sure that data is valid and meets acceptable standards of quality, will prevent costly errors, allow quick corrections when needed and contribute to a stable organisational climate as well as positive relationships with business partners. Adequate control procedures for EDI are therefore needed and they should help produce the intended advantages (Sokol, 1989, 1995).

\section{Hypothesis \#4: The level of internal integration is positively related to the advantages obtained from EDI.}

Economies of scale, improved production cycle and decreased transaction time are among the possible advantages of integrating a greater number of activities within the firm's value chain. This can also be true for quality improvements and inventory reduction (Kekre and Mukhopadhay, 1992).

\section{Hypothesis \#5: The level of external integration is positively related to the advantages obtained from EDI.}

The integration of EDI with all types of upstream and downstream partners is also considered important (Mackay, 1992). Increased external links allow the firm to capitalise on the investment made in EDI. Higher potential rewards can be obtained by firms implementing strategic applications (such as EDI) with an outward rather that an inward orientation (Bergeron, Buteau and Raymond,1991).

Hypothesis \#6: The level of imposition by business partners is negatively related to the advantages obtained from EDL

When implementing EDI is not a deliberate choice, crucial aspects of this implementation, such as the targeted business function, the timing and the choice of the value added network are not all under the firm's control. Benefits can thus be more slanted toward the firm that initiates EDI or imposes EDI on others. For instance, the implementation of EDI by a large manufacturer can significantly affect the bargaining power of distributors and thus lessen their advantages (Raymond and Blili, 1997).

Hypothesis \#7: There is a negative relationship between the level of imposition by business partners and the quality of the organisational context.

Earlier research (Bergeron and Raymond, 1992b) has suggested the existence of a negative link between the level of imposition and the organisational context of EDI. Indeed, the organisations upon whom EDI is imposed 
usually have less motivation and time to prepare for implementation of this technology. Level of imposition is thus expected to have both a direct and an indirect effect upon the attainment of EDI advantages.

\section{METHODOLOGY}

A two-phased design was used to investigate the research questions and to test the hypotheses. This design consisted of two surveys over a three-year period. In Phase 1, after pre-test interviews of ten EDI managers, questionnaires were mailed to 560 Canadian organisations. Following a recall letter, 140 useable responses were obtained for a response rate of $25 \%$. Three years later (Phase 2), the same questionnaire was sent to 119 of the 140 individuals who participated in Phase 1. In Phase 1, 21 questionnaires had initially been re-directed to respondents that were not clearly identified in terms of name or mailing address, thus the impossibility of reaching them for the second phase of this study. The cover letter explained the longitudinal aspect of the study, recalled their initial participation and asked again for their collaboration. As in Phase 1, a reminder was sent one week after the mailing, followed by phone calls. Sixty-five valid questionnaires were returned for a response rate of $55 \%$.

\section{Measurement of the research variables}

A number of scales were used to measure the variables hypothesised to influence the attainment of advantages from EDI (Appendix 1). The organisational support, implementation process, and control procedures were measured using the following statement: "Please indicate for each of the following statements the extent to which they are representative of the EDI implementation process in your organisation". Each scale was anchored on three points (no: 1, more or less: 2 , yes: 3 ) and a total score was obtained by averaging on all scales. The level of internal integration was determined by numbering the different types of EDI applications internal to the organisation, whereas the level of external integration numbered the different types of trading partners. For that purpose, the respondents were asked to indicate the exact types of EDI applications presently implemented (eg., purchasing, billing) as well as the types of business partners presently communicating with the organisation through EDI (eg. retailers, suppliers, clients).

The imposition scale contained one item asking the respondents to evaluate the truthfulness of the following statement: "The initial decision to implement EDI was imposed by your trading partner(s) " (no: 1, more or less: 2, yes: 3 ). This question was asked only in Phase 1 since the first contact of the organisations with EDI could not have changed over time.

The dependent variable included various benefits thought to be provided by EDI, in terms of administrative costs, transaction speed, information quality, operations management and strategic advantage (Appendix 2). The individual responsible for EDI in each enterprise was asked to rate the scales by the following statement: "Please evaluate the impact of the EDI implementation relative to the functions presently supported in your organisation", by indicating on a 5-point Likert scale to what extent each of these advantages had been obtained by the organisation (strong decrease: 1 , slight decrease: 2 , no change: 3 , slight increase: 4 , strong increase: 5 ). At both points in time (Phases 1 and 2), all alpha values of the independent and dependent variables were at or above an acceptable level (.7), except for the strategic advantage measure which had an alpha value of .5 in Phase 1, increasing to 7 in Phase 2.

\section{Data analysis}

Following Kenny's (1979) approach to correlation and causality in longitudinal research, the data analysis consists of five steps, as follows. The first step tests the stability of the independent variables of the model; it aims at determining if the mean level of factors remained the same over time. The second step concerns the stationarity of the intercorrelations among the independent variables; ideally, the strength of these relationships should remain the same over time. The third step addresses the stationarity of the correlations; its purpose is to investigate the causal structure of the hypothesised relationships over time, hoping that this structure does not change. The research hypotheses are tested at this step using bivariate analysis. The fourth step examines the spuriousness of the correlations; it consists of an exploration of cross-lagged correlations (ie., independent variable at time $t_{1}$ with dependent variable at time $t_{2}$, and independent variable at time 2 with dependent variable at $t_{1}$ ), with a critical look at the direction of any significant differences. The fifth and last step, is the test of the research model as a whole at both points in time using the partial least square (PLS) multivariate analysis technique. 


\section{Research Results}

\section{RESULTS}

The participating organisations come from various sectors as follows: $43.7 \%$ manufacturing, $15.6 \%$ distribution, $7.8 \%$ transportation, $6.3 \%$ wholesale, $4.7 \%$ financial institutions and $21.9 \%$ other. The respondents hold various management positions: $3.1 \%$ are CEO, $26.5 \%$ are IS managers, $20.3 \%$ are managers, $14.1 \%$ are EDI managers, $9.4 \%$ are computer managers and $26.6 \%$ others. The organisations had median annual sales of $\$ 200,000,000$, a median number of employees of 700 and a median annual EDI budget of $\$ 17,500$. Their EDI relationships were as follows: $76.2 \%$ with clients, $42,9 \%$ with suppliers, $23.8 \%$ with financial institutions, $22.2 \%$ with distributors, $18.8 \%$ with government agencies, $14.3 \%$ with shippers and $9.5 \%$ with others. On average, they had been using EDI for 6.5 years (whereas it was 3.5 years in Phase 1).

\section{Stability of variables}

The descriptive statistics for the independent variables of the final research model are presented in Table 1. Paired t-tests were used to test for the "stability" of the EDI success factors, ie. to determine if their mean level had changed over time (Kenny, 1979, p. 231). Matched sets of data were obtained by keeping only those 65 firms (out of the initial 140) who had answered the survey at both points in time.

The results first indicate that on average, the organisational support for EDI is perceived to be somewhat less favourable than it was three years ago. This can be attributed to the fact that the organisation is more familiar with EDI and the main support activities such as training were mostly realised during the initial implementation. The required level of support thus lessens over time. EDI is also presently more integrated internally than it was previously, as more functions other than ordering and billing were added gradually to increase the processing capabilities of the EDI system.

Table 2 presents the descriptive statistics showing the stability of the advantages obtained from EDI (dependent variables) over time. The one advantage to have shown a significant increase is the quality of information (in terms of accessibility, accuracy and service to clients). As firms become more experienced and integrate more internal functions through EDI, it is plausible that they find new ways and become more adept at extracting valuable information from the transaction data provided by this technology.

Table 1

Descriptive statistics of the independent variables $(N=65)$

\begin{tabular}{|c|c|c|c|c|c|}
\hline & $t_{1}$ & & $t_{2}$ & & \\
\hline & mean & s.d. & mean & s.d. & $T^{a}$ \\
\hline \multicolumn{6}{|l|}{ ORGANIZATIONAL CONTEXT' } \\
\hline Organisational support & 2.50 & 0.3 & 2.40 & 0.3 & $-2.06 *$ \\
\hline Implementation process & 2.35 & 0.5 & 2.39 & 0.5 & 0.43 \\
\hline Control procedures & 2.37 & 0.5 & 2.44 & 0.4 & 0.93 \\
\hline \multicolumn{6}{|l|}{ LEVEL OF INTEGRATION } \\
\hline Internal integration ${ }^{c}$ & 1.88 & 0.9 & 2.29 & 1.0 & $2.60 * *$ \\
\hline External integration ${ }^{d}$ & 1.78 & 1.2 & 2.06 & 1.3 & 1.31 \\
\hline IMPOSITION BY PARTNERS ${ }^{e}$ & 0.65 & - & $0.65^{f}$ & - & - \\
\hline
\end{tabular}

${ }^{*} \mathrm{p}<.05{ }^{* *} \mathrm{p}<.01 \quad{ }^{* * *} \mathrm{p}<.001$

${ }^{a}$ testing for stability, ie. equality of means (paired T-test)

${ }^{b} 1=$ no $2=$ more or less $3=y e s$

types of EDI transactions made by the organisation

types of EDI partners linked to the organisation

${ }^{\circ} 0=E D I$ implementation is voluntary

$1=E D I$ is imposed by one or more business partners

${ }^{f}$ Imposition $_{\mathfrak{L}}=$ Imposition $_{\mathfrak{t} 1}$ 


\section{Stationarity of intercorrelations}

Another comparison can be made by calculating the intercorrelations of the independent variables at $t_{1}$ and $t_{2}$, as presented in Table 3. The "stationarity" of these relationships, ie. determining if their strength has changed over time, can be ascertained by testing for the significance of the differences between the two sets of synchronous correlations (Kenny, 1979, p. 231). As suggested by Kenny (1979, p. 239), the Pearson and Filon test for stationarity was used since the standard Fischer's $z$ transformation is inappropriate when one is comparing correlated correlations. The results show that, among the organisational context factors, the relationship between the implementation process and the other two variables, namely organisational support and control procedures, has lessened significantly as indicated by the $z$ value. This could be attributed to the former variable's reflection of a prior organisational situation that has since evolved in terms of activities. Given that only 2 out of 10 intercorrelations differed significantly, a satisfactory level of stationarity is shown in that regard.

Table 2

Descriptive statistics of the dependent variables $(N=65)$

\begin{tabular}{llllll}
\hline & $\mathrm{t}_{1}$ & & $\mathrm{t}_{2}$ & & \\
\hline $\begin{array}{l}\text { EDI } \\
\text { ADVANTAGES }\end{array}$ & mean & s.d. & mean & s.d. & $\mathrm{T}^{\mathrm{b}}$ \\
$\mathrm{a}$ & & & & &
\end{tabular}

a

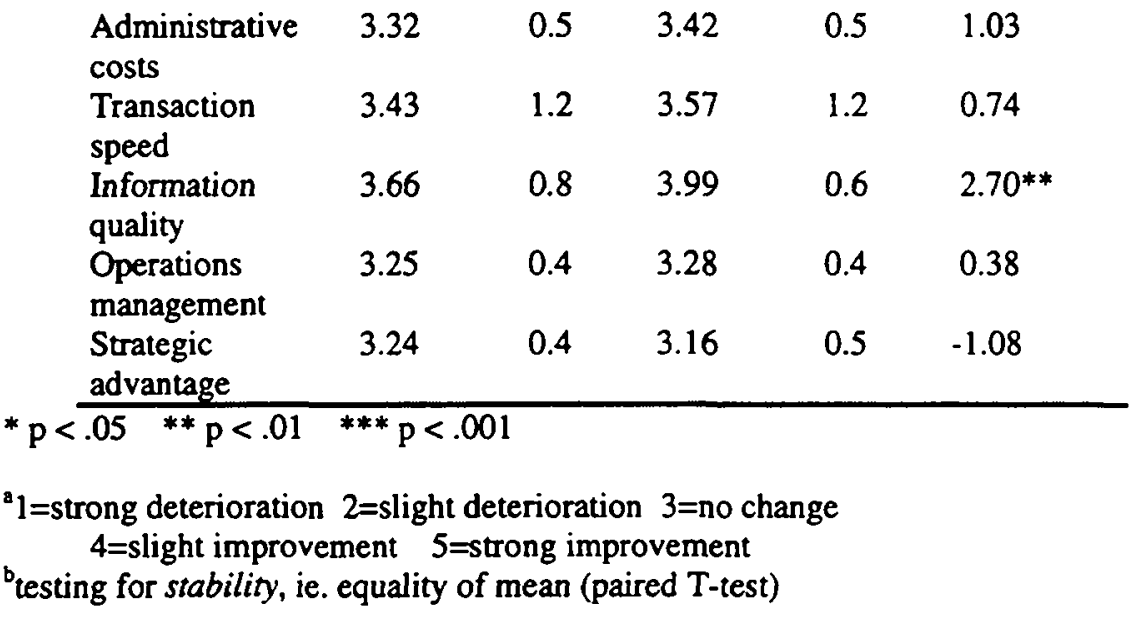

\section{Stationarity of correlations}

The research hypotheses can first be studied through bivariate analysis ie., by calculating the correlations between the independent and dependent variables in the final model. This being a longitudinal study, one is interested in ascertaining if the causal structure of the hypothesised relationships does not change over time. Again, the key assumption is that of stationarity, ie. that the strength of each relationship remains the same at both points in time.

Table 4 presents results pertaining to Hypotheses 1 to 6 at both points in time, linking six EDI success factors to the attainment of five types of advantages. The initial study, based on 140 firms, had confirmed the positive effect of the organisational context factors and the negative effect of imposition on attaining certain advantages from EDI, and in particular on the reduction of administrative costs. Integration was also shown to be globally determinant, and especially in attaining a strategic advantage from this technology.

Comparing the two matched sets of synchronous correlation coefficients, the $\mathrm{z}$ values obtained from the PearsonFilon statistic allow one to identify the significant changes in the hypothesised bivariate relationships between $t_{1}$ and $t_{2}$. Stationarity can be ascertained overall by observing that only eight correlations out of thirty changed significantly between $t_{1}$ and $t_{2}$.

A first change concerns the lessened impact over time of the implementation process on the managerial benefits of EDI (ie. information quality), as opposed to operational benefits (ie. transaction speed). Given that global information needs have been analysed initially, that organisational learning has occurred in the determination of more detailed needs and that operations managers have thus integrated EDI within their decision-making, the rigour of implementation of additional or complementary EDI functions seems less determinant in this regard. 
The second change of note regards the now significant impact of EDI control procedures in terms of information quality, operations management and strategic advantage, whereas this effect was absent at $t_{1}$. As EDI integrates more elements of the firm's value chain and more of its partners over time, risks increase and data integrity and security becomes more important, and thus the need to effectively control EDI operations.

The increased positive impact of internal integration on information quality is another significant change that has occurred in the sampled firms. As more functions such as procurement, inventory, shipping, billing and payments are linked through EDI, more data is rendered available, this data is more integrated and can be easily transformed into more comprehensive, timely and relevant information for decision-making. An analogous reasoning can be employed to explain the increased effect of external EDI integration on operations management. As EDI links the firm's value chain to the value chains of both its upstream and downstream partners, just-in-time (in manufacturing) or quick-response (in retailing) approaches can be implemented to reduce cycle times and improve service.

Looking at the bottom line of Table 3 in regard to Hypothesis 7, one sees that the initial negative influence of imposition on the organisational context has now become positive. At $t_{1}$, firms who implemented EDI under duress from their business partners provided a less favourable context. At $t_{2}$, these same firms now show a significantly higher level of organisational support for EDI. From a network perspective, EDI advantages can be unequal but also interdependent among business partners of unequal size and power (Raymond and Bergeron, 1996). Organisations upon whom EDI was imposed were found here to be significantly smaller than those who did so voluntarily. This change in the effect of imposition could reflect the realisation by larger firms who initiate EDI systems that they must eventually provide increased assistance (technical, financial, training) to their smaller partners, if this technology is to function efficiently and effectively to the benefit of all involved.

Regarding the effect of imposition on EDI advantages, partial rather than zero-order correlations were calculated in order to control for the intervening effect of the organisational context variables, assumed in the research model. Over time, imposition is shown here to lose its negative impact on administrative costs and operations management. This could be explained by the compensating effect of the increased assistance provided by large pivot firms in EDI networks to their partners. The latter could thus learn better and faster in regard to attaining both operational and managerial advantages from EDI. Another explanation is the possibility for the firm upon whom EDI was imposed to impose it in turn to its other business partners. The few benefits they obtained at the outset would thus be compensated later on.

\section{Spuriousness of correlations}

While the preceding correlational analysis tests the key stationarity assumption, ie. an unchanging causal structure, it is insufficient to rule out "spuriousness" as an alternative explanation of causal effects (Kenny, 1979, p.229). Non-spuriousness can be ascertained by testing for the equality of the cross-lagged. (as opposed to synchronous) correlations, using the same Pearson-Filon statistic. Rozelle and Campbell (1969) have pointed out the difficulty in interpreting significant cross-lagged differences. The results presented in Table 5 show that only four out of twenty-five possible differentials are non-zero. The level of spuriousness of the model was thus considered acceptable. Note that the imposition variable was not included in the cross-lagged analysis because it was assumed not to change over time. Given the equality of synchronous correlations in the corresponding four cases, the interpretation problem would center on the validity and stability of the variables involved (Kenny, 1973 , p. 234). One could eventually interpret the four relationships in the reverse causal order or even as a positive feedback loop. In this case, for instance, it would be plausible that attaining operational and strategic advantages in Phase 1 would "cause" a firm to add new EDI functions and partners, and thus lead to an increased level of integration in Phase 2. 
Table 3

Intercorrelation of the independent variables $(N=65)$

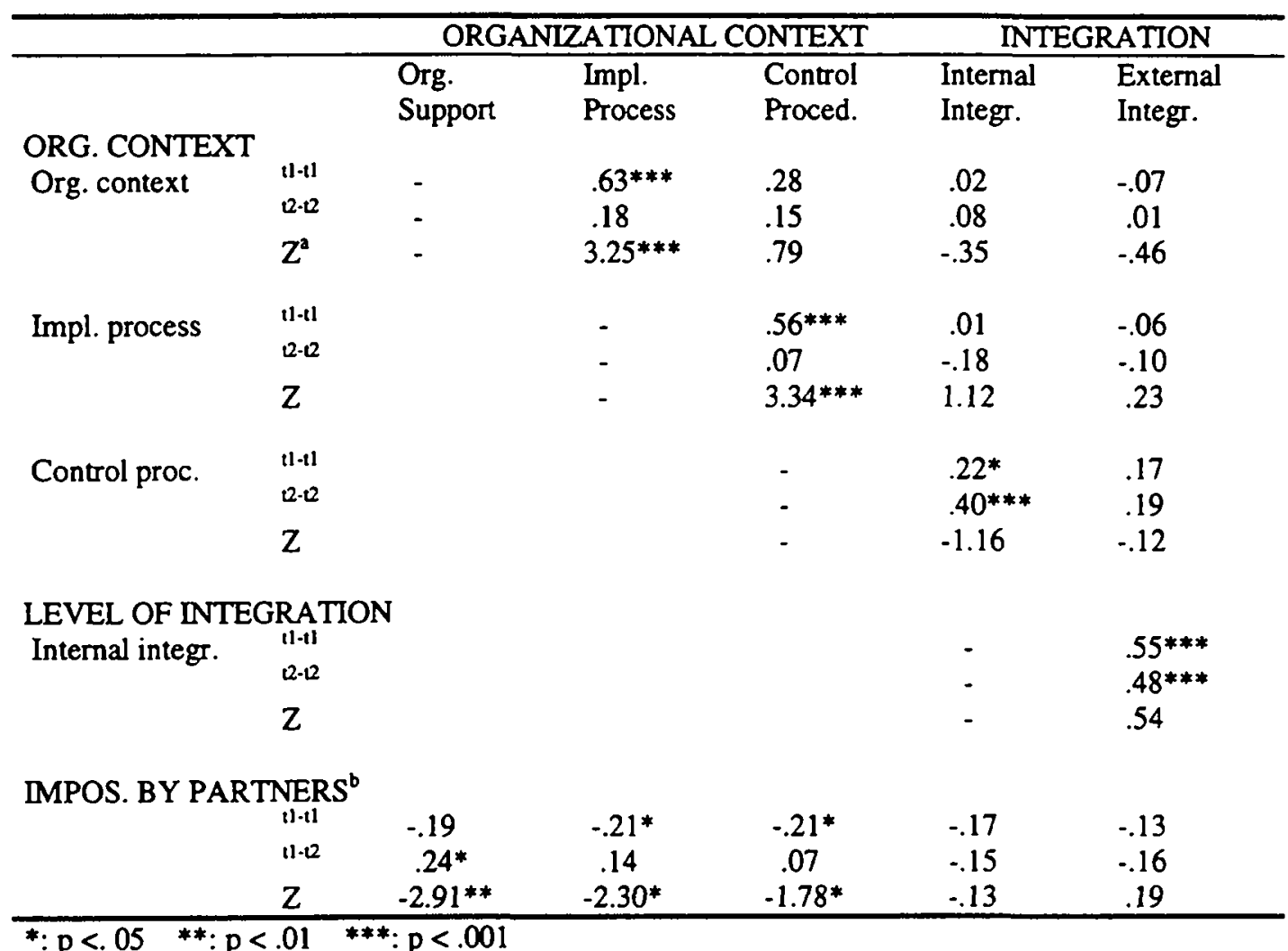

'Testing for stationarity, ie. equality of synchronous correlations (Kenny, 1979)

with:

$\mathrm{Z=(N)})^{1 / 2}\left(r_{14}-r_{23}\right) /\left(\left(1-r_{14}\right)^{2}+\left(1-r_{23}\right)^{2}-k\right)^{1 / 2}$
$k=\left(r_{12}-r_{24} r_{14}\right)\left(r_{34}-r_{24} r_{23}\right)+\left(r_{13}-r_{12} r_{23}\right)\left(r_{24}-r_{12} r_{14}\right)$

$\quad+\left(r_{12}-r_{13} r_{23}\right)\left(r_{34}-r_{13} r_{14}\right)+\left(\left(r_{13}-r_{14} r_{34}\right)\left(r_{24}-r_{34} r_{23}\right)\right.$

where:

variable 1: indep. var.tl variable 4: other indep. var.t1

variable 2: indep. var. 2 variable 3: other indep. var. .2

'Imposition $_{\mathbf{2}}=$ Imposition $_{\mathbf{l}}$ 
Table 4

Synchronous correlation of independent with dependent variables $(N=65)$

\begin{tabular}{|c|c|c|c|c|c|c|}
\hline & & \multicolumn{5}{|c|}{ EDI ADVANTAGES } \\
\hline . & & $\begin{array}{l}\text { Admin. } \\
\text { costs }\end{array}$ & $\begin{array}{l}\text { Trans. } \\
\text { speed }\end{array}$ & $\begin{array}{l}\text { Info. } \\
\text { qual. }\end{array}$ & $\begin{array}{l}\text { Oper. } \\
\text { manag. }\end{array}$ & $\begin{array}{l}\text { Strat. } \\
\text { advant. }\end{array}$ \\
\hline $\begin{array}{l}\text { Org. } \\
\text { support }\end{array}$ & $\begin{array}{l}t 1-t l \\
a-12 \\
Z^{a}\end{array}$ & $\begin{array}{l}.34^{* *} \\
.24 * \\
.61\end{array}$ & $\begin{array}{l}.19 \\
.09 \\
.60\end{array}$ & $\begin{array}{c}.26^{*} \\
.02 \\
1.42\end{array}$ & $\begin{array}{c}.26 * \\
.06 \\
1.20\end{array}$ & $\begin{array}{r}-.01 \\
.15 \\
-.92\end{array}$ \\
\hline $\begin{array}{l}\text { Implement. } \\
\text { process }\end{array}$ & $\begin{array}{c}t 1-t 1 \\
2-12 \\
Z\end{array}$ & $\begin{array}{l}.31 * * \\
.23 \\
.49\end{array}$ & $\begin{array}{l}.15 \\
.39 * * \\
-1.51\end{array}$ & $\begin{array}{l}.19 \\
-.15 \\
2.01 *\end{array}$ & $\begin{array}{l}.06 \\
-.24 \\
1.81^{*}\end{array}$ & $\begin{array}{l}-.29 * \\
-.16 \\
-.78\end{array}$ \\
\hline $\begin{array}{l}\text { Control } \\
\text { procedure }\end{array}$ & $\begin{array}{l}t 1-t 1 \\
2-2 \\
Z\end{array}$ & $\begin{array}{l}.41 * * * \\
.38 * * * \\
.20\end{array}$ & $\begin{array}{l}.19 \\
.14 \\
.30\end{array}$ & $\begin{array}{l}.09 \\
.34^{* *} \\
-1.52\end{array}$ & $\begin{array}{l}.12 \\
.27^{*} \\
-.90\end{array}$ & $\begin{array}{l}-.07 \\
.25^{*} \\
-1.89^{*}\end{array}$ \\
\hline $\begin{array}{l}\text { Internal } \\
\text { integr. }\end{array}$ & $\begin{array}{l}t 1-11 \\
2-12 \\
Z\end{array}$ & $\begin{array}{l}.16 \\
.25^{*} \\
-.53\end{array}$ & $\begin{array}{l}.09 \\
.06 \\
.17\end{array}$ & $\begin{array}{l}-.04 \\
.26^{*} \\
1.77^{*}\end{array}$ & $\begin{array}{r}.07 \\
.16 \\
-.52\end{array}$ & $\begin{array}{r}.19 \\
.21 \\
-.12\end{array}$ \\
\hline $\begin{array}{l}\text { External } \\
\text { integr. }\end{array}$ & $\begin{array}{c}11-11 \\
2-2 \\
Z\end{array}$ & $\begin{array}{c}.03 \\
.29 * \\
-1.54\end{array}$ & $\begin{array}{l}.20 \\
.12 \\
.46\end{array}$ & $\begin{array}{l}-.15 \\
.18 \\
-1.92 *\end{array}$ & $\begin{array}{l}.12 \\
.39 * * * \\
-1.68 *\end{array}$ & $\begin{array}{l}.30 * * \\
.18 \\
.73\end{array}$ \\
\hline $\begin{array}{l}\text { Impos. by } \\
\text { partners }\end{array}$ & $\begin{array}{c}\mathrm{tl}-\mathrm{tl} \\
\mathrm{t} 1-\mathrm{t} \\
Z\end{array}$ & $\begin{array}{l}-.40 * * \\
.17 \\
-3.39 * * *\end{array}$ & $\begin{array}{l}-.13 \\
-.03 \\
-.62\end{array}$ & $\begin{array}{r}-.14 \\
-.22 \\
.48\end{array}$ & $\begin{array}{l}-.26 * \\
.02 \\
-1.65^{*}\end{array}$ & $\begin{array}{r}-.05 \\
-.14 \\
.54\end{array}$ \\
\hline
\end{tabular}

$*: \mathrm{p}<.05 \quad * *: \mathrm{p}<.01 \quad * * *: \mathrm{p}<.001$

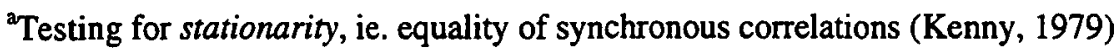

with:

$\mathrm{Z}=(\mathrm{N})^{1 / 2}\left(\mathrm{r}_{14}-\mathrm{r}_{23}\right) /\left(\left(1-\mathrm{r}_{14}{ }^{2}\right)^{2}+\left(1-\mathrm{r}_{23}{ }^{2}\right)^{2}-\mathrm{k}\right)^{1 / 2}$.

$k=\left(r_{12}-r_{24} r_{14}\right)\left(r_{34}-r_{24} r_{23}\right)+\left(r_{13}-r_{12} r_{23}\right)\left(r_{24}-r_{12} r_{14}\right)$

$+\left(r_{12}-r_{13} r_{23}\right)\left(r_{34}-r_{13} r_{14}\right)+\left(r_{13}-r_{14} r_{34}\right)\left(r_{24}-r_{34} r_{23}\right)$

where:

variable 1: EDI success factor $_{11}$ variable 4: EDI advantage ${ }_{t 1}$

variable 2: EDI success factor $_{12}$ variable $3:$ EDI advantage ${ }_{2}$

${ }^{b}$ Imposition $_{\mathrm{t} 2}=$ Imposition $_{\mathrm{t} 1}$ (partial correlation, controlling for organisational context variables) 
Table 5

Cross-lagged correlation of independent with dependent variables $(N=65)$

\begin{tabular}{|c|c|c|c|c|c|c|}
\hline & & \multicolumn{5}{|c|}{ EDI ADVANTAGES } \\
\hline & & $\begin{array}{l}\text { Admin. } \\
\text { costs }\end{array}$ & $\begin{array}{l}\text { Trans. } \\
\text { speed }\end{array}$ & $\begin{array}{l}\text { Info. } \\
\text { qual. }\end{array}$ & $\begin{array}{l}\text { Oper. } \\
\text { manag. }\end{array}$ & $\begin{array}{l}\text { Strat. } \\
\text { advant. }\end{array}$ \\
\hline $\begin{array}{l}\text { Org. } \\
\text { support }\end{array}$ & $\begin{array}{l}11-12 \\
0-11 \\
Z^{2}\end{array}$ & $\begin{array}{r}.05 \\
-.01 \\
.35\end{array}$ & $\begin{array}{l}.24^{*} \\
.09 \\
.89\end{array}$ & $\begin{array}{r}.03 \\
-.10 \\
.75\end{array}$ & $\begin{array}{r}-.11 \\
-.16 \\
.29\end{array}$ & $\begin{array}{r}.09 \\
-.06 \\
.86\end{array}$ \\
\hline $\begin{array}{l}\text { Implement. } \\
\text { process }\end{array}$ & $\begin{array}{c}11-0 \\
12-11 \\
Z\end{array}$ & $\begin{array}{r}.03 \\
.13 \\
-.58\end{array}$ & $\begin{array}{r}.05 \\
.16 \\
-.65\end{array}$ & $\begin{array}{c}.04 \\
.17 \\
-.75\end{array}$ & $\begin{array}{l}-.28 * \\
-.19 \\
-.54\end{array}$ & $\begin{array}{l}.00 \\
-.28^{*} \\
-1.68^{*}\end{array}$ \\
\hline $\begin{array}{l}\text { Control } \\
\text { procedure }\end{array}$ & $\begin{array}{c}11-12 \\
2-11 \\
Z\end{array}$ & $\begin{array}{c}.18 \\
.00 \\
1.08\end{array}$ & $\begin{array}{r}.01 \\
.09 \\
-.46\end{array}$ & $\begin{array}{r}.07 \\
-.06 \\
.75\end{array}$ & $\begin{array}{r}.02 \\
-.20 \\
1.30\end{array}$ & $\begin{array}{r}-.05 \\
.12 \\
-.97\end{array}$ \\
\hline $\begin{array}{l}\text { Internal } \\
\text { integr. } \\
\text { External } \\
\text { integr. }\end{array}$ & $\begin{array}{c}11 \cdot 02 \\
2-41 \\
Z \\
21-02 \\
0-41 \\
Z\end{array}$ & $\begin{array}{c}-.08 \\
.26^{*} \\
-2.01^{*} \\
.03 \\
.05 \\
-.11\end{array}$ & $\begin{array}{l}-.07 \\
.18 \\
-1.46 \\
-.09 \\
.26 * \\
-2.09 *\end{array}$ & $\begin{array}{c}.04 \\
.12 \\
-.46 \\
-.10 \\
.12 \\
-1.26\end{array}$ & $\begin{array}{r}.04 \\
.08 \\
-.23 \\
.19 \\
.06 \\
.76\end{array}$ & $\begin{array}{l}-.05 \\
.27^{*} \\
-1.91^{*} \\
.02 \\
.08 \\
-.35\end{array}$ \\
\hline $\begin{array}{l}\text { Impos. by } \\
\text { partners }\end{array}$ & $\begin{array}{c}11 \cdot 02 \\
11 \cdot 01 \\
Z\end{array}$ & - & $\begin{array}{l}- \\
-\end{array}$ & - & $\begin{array}{l}- \\
-\end{array}$ & - \\
\hline
\end{tabular}

'Testing for spuriousness, ie. non-equality of cross-lagged correlations (Kenny, 1979) with:

$\mathrm{Z}=(\mathrm{N})^{1 / 2}\left(\mathrm{r}_{14}-\mathrm{r}_{23}\right) /\left(\left(1-\mathrm{r}_{14}\right)^{2}+\left(1-\mathrm{r}_{23}\right)^{2}-\mathrm{k}\right)^{1 / 2}$

$k=\left(r_{12}-r_{24} r_{14}\right)\left(r_{34}-r_{24} r_{23}\right)+\left(r_{13}-r_{12} r_{23}\right)\left(r_{24}-r_{12} T_{14}\right)$

where:

$+\left(r_{12}-r_{13} r_{23}\right)\left(r_{34}-r_{13} r_{14}\right)+\left(r_{13}-r_{14} r_{34}\right)\left(r_{24}-r_{34} r_{23}\right)$

variable 1: EDI success factor $_{t 1}$ variable $4: \mathrm{EDI}_{\text {advantage }}$

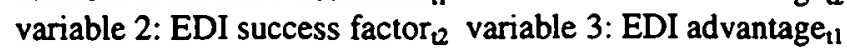

${ }^{\text {IImposition }} \mathrm{Q}=$ Imposition $_{\mathfrak{t l}}$ (cross-lagged analysis is inappropriate for variables that do not change over time)

\section{Multivariate Analysis}

A more comprehensive and powerful validation of the research model involves the multivariate analysis of the structural equations. The partial least squares (PLS) technique was chosen for its emphasis on theory development and its robustness, as it allows for small samples, non-interval scaled and non-multivariate normal data (Higgins, Barclay and Duxbury, 1991). Two sets of correlations and path coefficients corresponding to the research hypotheses were thus obtained. The notion of "EDI advantages" is defined as a global construct (latent variable) whose meaning is reflected in the five advantages types measured in both the initial and the present study. Hence, the results of the two PLS analyses also provide the loading for each type of advantage, ie. its correlation with the global construct.

The validity and explanatory power of the research model can be assessed by comparing the path coefficients and the loadings obtained from the $t_{1}$ and $t_{2}$ data. As opposed to the bivariate analysis, all 140 firms in the initial sample were kept for the PLS analysis of the time 1 data because no statistical tests requiring paired data were involved. These results are presented in Table 6.

The first research hypothesis of the initial study remains confirmed at the second point in time, as indicated by significant path coefficients. There is thus strong evidence for a causal link between a firm's level of organisational support for EDI and its attainment of advantages from this technology. This is not so however, in regard to Hypothesis 2 . The significant effect of the implementation process at $t_{1}$ is attenuated three years later. 
The rigour of the EDI implementation process is determinant for the initial applications but not for later ones, probably because of the experience previously gained by the firm.

Conversely, EDI control procedures take on added importance over time, Hypothesis 3 being more strongly confirmed at $\mathrm{t}_{2}$ than earlier. As EDI affects more of the firm's core operations and strategy over time, questions of data security and integrity should take precedence in determining the successful use of this technology. Overall, a causal link between the organisational context and the benefits obtained from EDI seems present, with a relatively stable effect of organisational support, a decreasing effect of the implementation process and an increasing effect of control procedures over time.

As for Hypothesis 4, the path coefficient initially linking internal integration to EDI advantages loses its significance over time. Note however that the corresponding correlation coefficient between these two variables remains significant. To interpret this result, one should remember that the mean level of internal integration has significantly increased over the observed time period (Table 1) and that it is strongly correlated to external integration (Table 3). As predicted in Hypothesis 5, greater upstream and downstream integration with multiple business partners would lead to greater benefits from EDI. Adding a new type of EDI partner (eg. transporters) might also mean that new organisational functions (eg. shipping, receiving) are integrated through EDI technology. Initially, both variables are equally determinant, whereas internal integration is preempted by external integration at the second point in time.

Contrary to the sixth research hypothesis confirmed in the initial study, imposition has after a while no significant impact on the attainment of EDI advantages. With the assistance of their partners, firms that envisioned EDI only as an added cost to satisfy important clients or suppliers possibly learn to better manage and seize the opportunities provided by this technology. The same can be said regarding the effect of this variable upon the organisational context of EDI (Hypothesis 7). Initially, firms who did not implement EDI voluntarily presented a less favourable context, a less rigorous implementation process and less control procedures; this is not the case now. In fact, as discussed in the bivariate analysis (Table 3), imposition seems to have a delayed positive impact on the level of organisational support for EDI that can be attributable, for instance, to outside assistance obtained from a business partner.

The results of PLS analyses also provide reliability and validity assessments. Looking at the initial loadings of the EDI advantage measures, only one did not reach the .5 level for acceptable reliability, namely the strategic advantage. This last measure was more laden with random error, with a Cronbach's alpha of .50, at $t_{1}$, compared to .70 at $\mathrm{t}_{2}$. However, it could not be removed or revised due to the longitudinal nature of the study. While the reliability of the strategic advantage measure did in fact increase sufficiently in the second phase of the study, the loading of the transaction speed measure did the opposite by falling below the .5 level. The changes in the loadings could be interpreted more substantively by the relative importance of certain types of EDI advantages at different points in time. Initially, the operational aspect would be most important, ie. the firm wants to reduce costs and time delays. Later, managerial and strategic aspects come into play, ie. the firm realises it can manage its operations better and gain a competitive advantage through EDI.

The overall validity of the measurement model is confirmed at both points in time by the significant and comparable percentages of variance in EDI advantages that are explained by the independent variables $\left(27 \%\right.$ at $t_{1}$ and $30 \%$ at $t_{2}$ ). As evidence for discriminant validity, the average variance extracted by the measures of EDI advantages is greater than the variance shared between this construct and all other constructs in the research model (obtained by squaring the correlations in Table 6). Finally, the EDI advantages construct shows an acceptable level of internal consistency, using a reliability coefficient (rho) developed by Fornell and Larcker (1981).

In summary, the proposed causal model shows a satisfactory level of stationarity over time, both with respect to intercorrelations and correlations among the independent and the dependent variables. In addition, the low number of cross-lagged correlations between the two phases (ie., the non-spuriousness) supported the causal direction of the model. 
Table 6

Path analyses (PLS) of the research model

\begin{tabular}{|c|c|c|c|c|}
\hline & $\begin{array}{c}t_{1} \\
(N=140)\end{array}$ & $\begin{array}{c}t_{2} \\
(N=65) \\
\end{array}$ & $\begin{array}{c}\mathrm{t}_{1} \\
(\mathrm{~N}=140)\end{array}$ & $\begin{array}{c}\mathrm{t}_{2} \\
(\mathrm{~N}=65)\end{array}$ \\
\hline & \multicolumn{2}{|c|}{ correlations } & \multicolumn{2}{|c|}{ path coefficients } \\
\hline \multicolumn{5}{|l|}{ Organisational support } \\
\hline (H1) with EDI advantages & $.290^{* * *}$ & .164 & $.129 * * *$ & $.115^{*}$ \\
\hline \multicolumn{5}{|l|}{ Implementation process } \\
\hline (H2) with EDI advantages & $.283^{* * *}$ & -.021 & $.145^{* * *}$ & -.106 \\
\hline \multicolumn{5}{|l|}{ Control procedures } \\
\hline (H3) with EDI advantages & $.272^{* * *}$ & $.421^{* * *}$ & $.081 * * *$ & $.352^{* * *}$ \\
\hline \multicolumn{5}{|l|}{ Internal integration } \\
\hline (H4) with EDI advantages & $.301 * * *$ & $.293^{* *}$ & $.167 * *$ & .036 \\
\hline \multicolumn{5}{|l|}{ External integration } \\
\hline (H5) with EDI advantages & $.309 * * *$ & $.378 * * *$ & $.152 * * *$ & $.312 * * *$ \\
\hline \multicolumn{5}{|l|}{ Imposition by partners } \\
\hline (H6) with EDI advantages & $-.317 * * *$ & .067 & $-.219 * * *$ & .073 \\
\hline \multicolumn{5}{|l|}{ Imposition by partners } \\
\hline (H7) with Org. support & $-.181^{*}$ & $.245^{*}$ & $-.181 * * *$ & $.245^{* * *}$ \\
\hline with Impl. process & $-.192 * *$ & .065 & $-.192 * * *$ & .065 \\
\hline with Control proc. & $-.159 *$ & .065 & $-.159 * * *$ & .065 \\
\hline
\end{tabular}

EDI advantages

Administrative costs $\quad$\begin{tabular}{ll}
.759 \\
\hline
\end{tabular}

$\begin{array}{lrr}\text { Transaction speed } & .641 & .375\end{array}$

Information quality $\quad .553 \quad .666$

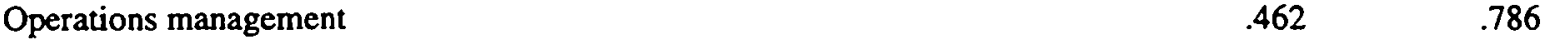

$\begin{array}{lrr}\text { Strategic advantage } & .195 & .629\end{array}$

$\begin{array}{lll}\text { R square } & .267 & .296\end{array}$

Aver. variance extracted $^{2} \quad$.449 $\quad .435$

$\begin{array}{lll}\text { Reliability coefficient }^{\mathrm{b}} & .704 & .785\end{array}$

${ }^{a} \Sigma_{i=1, n}$ loading $_{i}{ }^{2} / \mathbf{n}$

${ }^{b} \sum_{i=1, n}$ loading $\left._{i}\right)^{2} /\left(\left(\Sigma_{i=1, n} \text { loading }_{i}\right)^{2}+\Sigma_{i=1, n}\left(1-\right.\right.$ loading $\left.\left._{i}{ }^{2}\right)\right)$

\section{CONCLUSION}

Longitudinal results on EDI implementation were obtained by twice surveying 65 organisations over a three-year period. In Phase 1, all factors are positive determinants of EDI except for imposition which shows a negative effect on both EDI advantages and organisational context variables (organisation supporh, implementation process and control procedures). In Phase 2, the implementation process, the level of internal integration and imposition by business partners lose their importance. In this second phase, organisational support, control procedures and external integration are the only significant direct determinants, with imposition having a unique positive effect on organisational support. In a way, security and external integration could become the major stumbling blocks of Electronic Commerce and therefore much care should be taken to improve these crucial aspects of electronic commerce.

Having observed EDI in organisations over a three-year period, this study has implications for both researchers and practitioners. The basic validity of a research model that includes the organisational context, integration and 
imposition of EDI as essential determinants of success has been confirmed, with evidence of causality provided by the longitudinal nature of the study. Increased advantages can be attained through EDI, if organisations can be persuaded to implement, use and manage this technology as an opportunity to enhance business processes and partnerships. Using this model as a foundation, we see that further research is needed. The model could be enriched to include other potential factors emanating from a network point of view, or from a broader theoretical perspective. Added work should also be done on the measurement of EDI advantages, especially those of a strategic nature.

From a practical point of view, there are still too few organisations that have truly profited from electronic commerce. Too many firms, especially smaller ones, still consider EDI simply as an added cost of doing business. As EDI migrates into the Internet and on to extranets, future extensions of EC networks initialised by large organisations and normalisation efforts should include EC planning, implementation and training frameworks. These frameworks would guide firms on how to provide a favourable context for EC, and how to better integrate their intra and inter-organisational systems to fully benefit from this new form of commerce.

\section{REFERENCES}

Adolphson, D. and Hansen, J.V. "Evaluating Software Controls for EDI". European Journal of Operational Research, 51, 1, March 1991, $42-46$.

Banerjee, S., and Golhar, D.Y., Electronic Data Interchange: Characteristics of User and Nonusers, Information \& Management, 26 (1994) pp. 65-74

Bergeron, F., Buteau, C., Raymond, L. "Identification of Strategic Information Systems Opportunities: Applying and Comparing Two Methodologies,"_MIS Quarterly, Vol. 15, No. 1, March 1991.

Bergeron, F. and Raymond, L. "Planning of Information Systems to Gain a Competitive Edge". Journal of Small Business Management, 30, 1, 1992a, 21-26.

Bergeron, F. and Raymond, L. "The Advantages of Electronic Data Interchange". Data Base, 23, 4, 1992b, 1931.

Cavaye, A.M. and Cragg, P.B., «Factors Contributing to the Success of Customer Oriented Interorganizational Systems », Journal of Strategic Information Systems, (4,1) March 1995, pp. 13-30.

Champy, J., Reengineering Management, Harper Business, New York,.

Fornell, c. and Larcker, D. "Evaluating Structural Equation Models with Unobservable Variables and Measurement Error". Journal of Marketing Research, 18, 1981, 39-50.

Gebauer, J., «Internet-Based EDI », Briefings Paper 96-BP-001, Fisher Center For Information Technology and Management, December 1996.

Higgins, C.A., Barclay, D.W. and Duxbury, L.E. "An Introduction to the Partial Least Squares Approach to Causal Modeling". Working paper, School of Business Administration, University of Western Ontario, London, Canada, 1991.

Kalakota, R. and Whinston, A.B. Frontiers of Electronic Commerce ,Addison-Wesley Publishing Company, New York, 1996.

Kekre, S. and Mukhopadhyay, T. "Impact of EDI Technology on Quality Improvement and Inventory reduction Programs: A Field Study". International Journal of production Economics, 28, 3, December 1992, 265282.

Kenny, D.A., Correlation and Causality, John Wiley and Sons, N.Y., 1979.

Klein, S. "A Conceptual Framework for the Assessment of EDI". Proceedings of the 25th Hawaii International Conference on System Sciences, Vol. IV, Kauai, Hawaii, 1992, 369-379.

Mackay, D.R. "The Contribution of EDI to the Structural Change of the Australian Automotive Industry". Proceedings of the Third Australian Conference on Information Systems, University of Wollongong, Australia, 5-8 October 1992, 633-652.

Mukhopadhyay, T., Kekre, S., Kalathur, S., « Business Value of Information Technology : A Study of Electronic Data Interchange, MIS Quarterly, (19:2), June 1995, pp. 137-156.

O'Callaghan, Ramon, Kaufmann, Patrick J., Konsynski, Benn R., "Adoption Correlates and Share Effects of Electronic Data Interchange Systems in Marketing Channels", Journal of Marketing, Vol. 26, No. 2, April 1992, pp. 45 - 56.

Raymond, F. and Bergeron, F. "EDI Success in Small and Medium-sized Enterprises: A Field Study", Journal of Organisational Computing and Electronic Commerce, 6, 2, 1996, pp.161-172.

Raymond, L. and Blili, S. "Adopting EDI in a Network Organisation: The Case of Subcontracting SMEs". European Journal of Purchasing and Supply Management, 3, 3, 1997, pp.165-175.

Raymond, L. and Bergeron, F. "Global Distribution Systems: A Field Study of their Use and Advantages in Travel Agencies". Journal of Global Information Management, 5, 4, 1997, 23-32. 
Riggins, F.J. and Mukhopadhyay, T. "The Impact of Unequal Interdependent Benefits from Interorganizational Systems". Proceedings of the 27th Hawaii International Conference on System Sciences, Vol. IV, Wailea, Hawaii, 1994, 875-884.

Rozelle, R.M. and Campbell, D.T. "More Plausible Rival Hypotheses in the Cross-lagged Panel Correlation Technique". Psychological Bulletin, 71, 1969, 74-80.

Sanders, N.R. "Merging EDI with JT: The Impact on U.S. Manufacturing". Journal of Applied Business Research, 8, 2, Spring 1992, 133-137.

Skagen, A., "Nurturing Relationships, Enhancing Quality with Electronic Data Interchange", Management Review, Vol:78, No. 2, February 1989, pp. 28-32.

Senn, J.A. "Electronic Data Interchange: The Elements of Implementation", Information Systems Management, Winter 1992, 45-53.

Sokol, P.K., EDI: The Competitive Edge, McGraw-Hill, New-York, 1989.

Sokol, P.K. From EDI to Electronic Commerce - A Business Initiative , McGraw Hill, New York, 1995.

Swatman, Paula M. C., Swatman Paul A., "Integrating EDI into the Organisation's Systems : A Model of the Stages of Integration", Proceedings of the $12^{\text {th }}$ International Conference on Information Systems, New York, 1991, pp. 141 - 153.

Venkatraman, N., Zaheer, A., "Electronic Integration and Strategic Advantage: A Quasi-Experimental Study in the Insurance Industry, Information Systems Research, Vol. 1, No. 4, December 1990, pp. 377-393.

Vitalari, Nicholas P., "The Need for Longitudinal Designs in the Study of Computing Environments", Research Methods in Information Systems, opus citus, 1985, pp. $243-265$.

Wheatman, V., «EDI Over the Internet: McKesson Case Study », The Gartner Group Electronic Commerce Strategies Research Note, June, 1996.

Zaheer, A. and Venkatraman, N., "Determinants of Electronic Integration in the Insurance Industry: An Empirical Test, Management Science, (40:5), May 1994, pp. 549-566.

\section{Acknowledgments}

The authors wish to thank the Government of Quebec (FCAR), and the EDI Council of Canada for their collaboration and support. An earlier, abridged version of this paper was presented at 9th International Conference of the Information Resources Management Association, Boston, Massachusetts, 1998. 
Organisational Support

Appendix 1

Organisational Context of EDI

- training of top-management

- training of department heads

- training of data processing personnel

- training of users

- top-management is favourable

- top-management supports the implementation project

- working group responsible for implementation

- EDI managed by a specific organisational unit

- individual(s) specifically assigned to manage EDI

- cooperation with commercial partners during implementation

- cooperation among departments during implementation

Implementation Process

- analysis of strategic and operational impacts of EDI

- use of pre-defined transmission standards and protocols

- availability of an EDI implementation guide

- development of a prototype before implementation

- pilot project conducted before definitive implementation

- in-house tests, i.e. only within the organisation

- external tests, i.e. with trading partners

- analysis of initial transactions

- appreciation of system quality by users

- measure of response time

- measure of error rate

- measure of transaction costs

Control Procedures

- transaction entry and control tasks assigned to different individuals

- transactions recorded before transmission

- transaction acknowledgments by partners are recorded

- backup of transactions

- backups stored outside the organisation

- transaction entry and safekeeping tasks assigned to different individuals

- only formally authorised personnel may use EDI

- access code necessary to use EDI

- authorisation required for special transactions, e.g. exceeding a certain limit

- user authorised for limited types of transactions

- transactions bear a user stamp

- transactions bear a date stamp

- transactions bear a time stamp

- transactions made only within pre-determined time period 
Appendix 2

Advantages of EDI

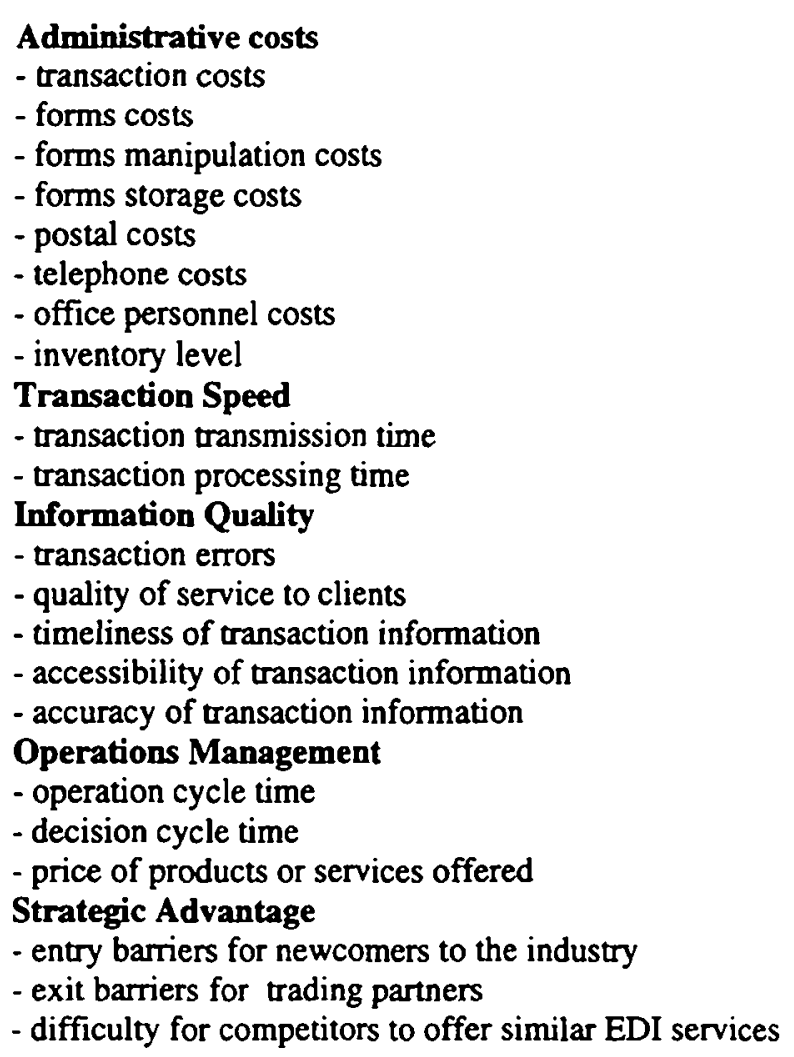

